UDK: 655.3

DOI: https://doi.org/10.24867/13EF01Hudak

\title{
KONTROLA KVALITETA OTISAKA OFSET ŠTAMPE U ŠTAMPARIJI BALATON ŠTAMPA
}

\section{OFFSET PRINT QUALITY CONTROL IN PRINT HOUSE BALATON ŠTAMPA}

Boris Hudak, Nemanja Kašiković, Rastko Milošević, Fakultet tehničkih nauka, Novi Sad

\section{Oblast - GRAFIČKO INŽENJERSTVO I DIZAJN}

Kratak sadržaj - U radu je izvršena kontrola kvaliteta otisaka dobijenih postupkom ofset štampe pomoću grafičkog sistema KBA Rapida 74 na niklapet $80 \mathrm{~g} / \mathrm{m}^{2}$ hartiji kontrolisanjem parametara optičke gustine $i$ sivog balansa. Ispitivanje je vršeno na uzorcima tabaka dobijenih iz štamparije Balaton Štampa. Analiziranje uzoraka je izvršeno sa Techkon SpectroDens uređajem.

Ključne reči: Ofset tabačna štampa, kontrola kvaliteta otisaka

\begin{abstract}
This paper gives analysis of the quality control of prints on nickel paper $80 \mathrm{~g} / \mathrm{m} 2$ by optical density and gray balance. The examination was performed on samples of sheets obtained from the printing house Balaton Štampa from Novi Sad. The printing house uses sheet-fed offset printing machine. Sample measurement was done with a Techkon SpectroDens device.
\end{abstract}

Keywords: Sheet-fed offset printing, print quality control

\section{UVOD}

Grafička tehnologija se bavi projektovanjem grafičkih proizvoda, tehnologijom štampe, izdavaštvom, ambalažom, primenom i ispitivanjem grafičkih materijala, tehničkim rešenjima uređaja i sistema u kojima se primenjuju nova saznanja i tehnike [1]. Proces prenošenja boje na papir (ili neki drugi materijal na koji se štampa) posredstvom jedne štamparske forme označava se kao štampanje [2].

Prilikom postupka štampanja potrebno je da se vrši redovna kontrola svih parametara kako bi se na kraju dobio zadovoljavajući otisak. Kontrola kvaliteta štampe vrši se analizom kontrolnih mernih traka pomoću mernih uređaja kao što su denzitometri, spektrofotometri i kolorimetri.

\section{EKSPERIMENTALNI DEO}

Otisci koji su korišćeni za eksperimentalni deo istraživanja štampani su u štampariji Balaton Štampa koja se nalazi u Novom Sadu. Ispitivani otisci su štampani na ofset štamparkoj mašini KBA RAPIDA 74 (slika 1.) koja ima pet štamparskih jedinica i jedinicu za VD i UV lak. CtP koji je korišćen za dobijanje štamparskih formi je SCREEN Plate Rite 4300 koji koristi 32 IR laserske diode. Papir koji

\section{NAPOMENA:}

Ovaj rad proistekao je iz master rada čiji mentor je bio dr Nemanja Kašiković, vanr. prof. je korišćen u ispitivanju je etiketni niklapet $80 \mathrm{~g} / \mathrm{m}^{2}$, premazni, a boje su Sun Chemical.

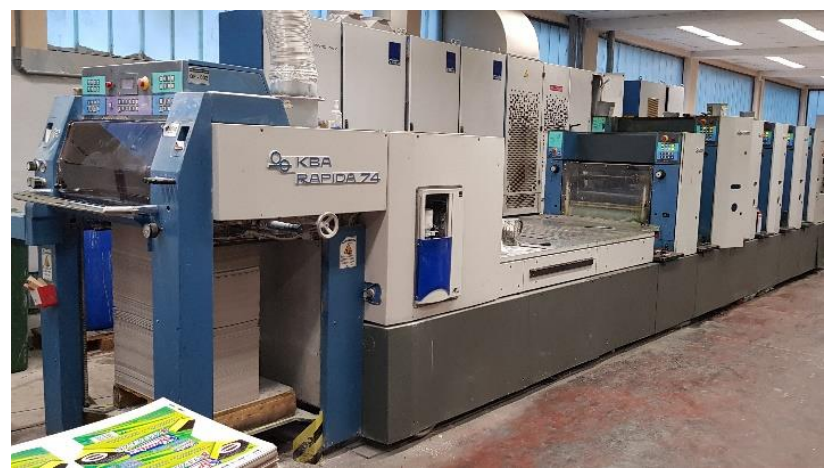

Slika 1. Grafički sistem KBA RAPIDA 74

Kontrola kvaliteta se radila na mesečnom nivou, pošto je izabran posao koji se štampa više puta $u$ toku jednog meseca pri čemu se koristila ista priprema, štamparske forme, boje i ista tabačna mašina KBA Rapida 74. Iz odštampanih naslaga tabaka, pri svakoj početnom i ponovnom štampanju (ukupno četiri štampanje), uzimalo se deset tabaka (svaki hiljaditi).

Analiza odštampanih uzoraka je izvršena pomoću uređaja izvršena pomoću spektrofotometra Teckhon SpectroDens, koji koristi osvetljenje D65, standardni ugao posmatranja od $10^{\circ}$ i mernu geometriju $\mathrm{d} / 8$, pri čemu su se merili parametri optičke gustine i sivog balansa.

\section{REZULTATI MERENJA}

\subsection{Merenje optičke gustine}

Optička gustina boje zavisi od tona boje, debljine nanosa boje i vrste i koncentracije pigmenata. Pošto je ton boje $\mathrm{u}$ skali propisan, a koncentracija pigmenata u štamparskoj boji nepromenljiva, $\mathrm{u}$ procesu štampe preostaje jedino debljina nanosa boje kao promenljiva pomoću koje može da se utiče na kvalitet [3]. Rezultati merenja optičke gustine na poljima punog tona $(100 \%$ raster tonske vrednosti) ukazuju na veoma male razlike između otisaka kroz tiraž. Merenje je vršeno za četiri procesne i jednu Pantonr boju.

Tabela 1. Merenja optičke gustine za cijan - tiraž I

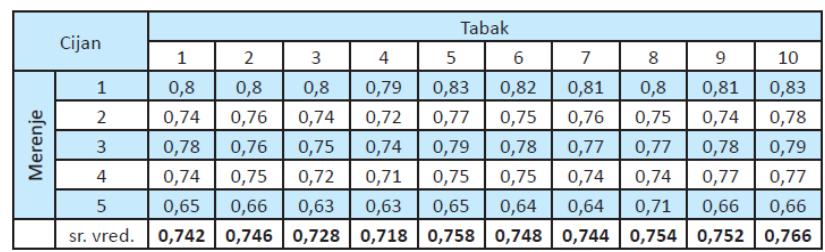


Kod upoređivanja dobijenih srednjih rezultata koji se nalaze $u$ tabeli 1 . vidi se da je nanos cijan boje $u$ celokupnom tiraž I ujednačen, što se može videti i u tabeli 2.

Tabela 2. Merenja optičke gustine za cijan - tiraž II

\begin{tabular}{|c|c|c|c|c|c|c|c|c|c|c|c|}
\hline \multirow{2}{*}{\multicolumn{2}{|c|}{ Cijan }} & \multicolumn{10}{|c|}{ Tabak } \\
\hline & & 1 & 2 & 3 & 4 & 5 & 6 & 7 & 8 & 9 & 10 \\
\hline \multirow{6}{*}{$\Sigma$} & 1 & 0,88 & 0,89 & 0,9 & \begin{tabular}{|l}
0,92 \\
\end{tabular} & 0,9 & 0,89 & 0,9 & 0,88 & 0,92 & 0,89 \\
\hline & 2 & 0,79 & 0,8 & 0,82 & 0,82 & 0,82 & 0,82 & 0,82 & 0,81 & 0,84 & 0,84 \\
\hline & 3 & 0,8 & 0,81 & 0,82 & 0,83 & 0,82 & 0,83 & 0,82 & 0,81 & 0,85 & 0,83 \\
\hline & 4 & 0,77 & 0,79 & 0,81 & \begin{tabular}{|l}
0,81 \\
\end{tabular} & 0,8 & 0,81 & 0,8 & 0,8 & 0,82 & 0,83 \\
\hline & 5 & 0,71 & 0,71 & 0,73 & \begin{tabular}{|l}
0,71 \\
\end{tabular} & 0,73 & 0,72 & 0,72 & 0,72 & 0,73 & 0,74 \\
\hline & r. vre & 0,79 & 0,8 & 0,816 & 0,818 & 0,814 & 0,814 & 0,812 & 0,804 & 0,832 & 0,826 \\
\hline
\end{tabular}

Tabela 3. Merenja optičke gustine za cijan - tiraž III

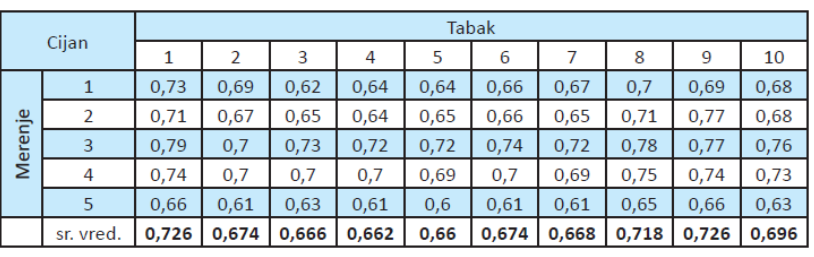

Kod upoređivanja dobijenih srednjih rezultata koji se nalaze u tabeli 3. takođe vidimo da je optička gustina za cijan boju tokom celokupnog tiraža ujednačena.

Tabela 4. Merenja optičke gustine za cijan - tiraž IV

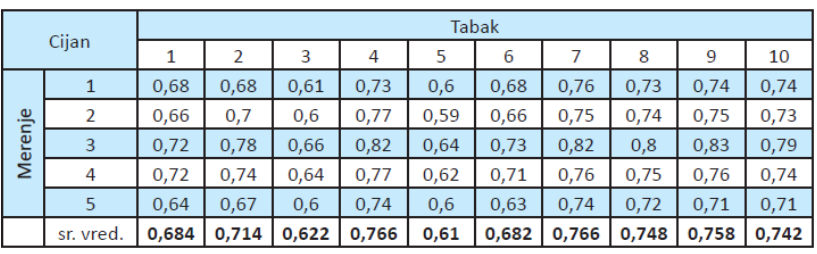

Kod upoređivanja dobijenih srednjih rezultata koji se nalaze u tabeli 4. vidi se minimalnih odstupanja, ali može da se kaže da je optička gustina kroz celokupan tiraž ujednačena.

Merenja optičke gustine za magentu, predstavljene su $u$ tabelama 5-8.

Tabela 5. Merenja optičke gustine za magentu - tiraž I

\begin{tabular}{|c|c|c|c|c|c|c|c|c|c|c|c|}
\hline \multirow{2}{*}{\multicolumn{2}{|c|}{ Magenta }} & \multicolumn{10}{|c|}{ Tabak } \\
\hline & & 1 & 2 & 3 & 4 & 5 & 6 & 7 & 8 & 9 & 10 \\
\hline \multirow{6}{*}{$\Sigma$} & 1 & 1,19 & 1,18 & 1,16 & 1,16 & 1,23 & 1,19 & 1,19 & 1,23 & 1,26 & 1,22 \\
\hline & 2 & 1,26 & 1,25 & 1,27 & 1,23 & 1,29 & 1,25 & 1,3 & 1,35 & 1,35 & 1,3 \\
\hline & 3 & 1,2 & 1,19 & 1,2 & 1,17 & 1,24 & 1,21 & 1,23 & 1,29 & 1,31 & 1,22 \\
\hline & 4 & 1,27 & 1,26 & 1,27 & 1,23 & 1,32 & 1,28 & $\begin{array}{ll}1,31 \\
\end{array}$ & 1,37 & 1,38 & 1,33 \\
\hline & 5 & 1,23 & 1,19 & 1,22 & 1,18 & 1,25 & 1,22 & 1,24 & 1,3 & 1,31 & 1,23 \\
\hline & sr. vred & 1,23 & 1,214 & \begin{tabular}{|l|l|}
1,224 \\
\end{tabular} & 1,194 & 1,266 & 1,23 & 1,254 & 1,308 & 1,322 & 1,26 \\
\hline
\end{tabular}

Kod upoređivanja dobijenih srednjih rezultata koji se nalaze u tabeli 5. vidi se da postoje minimalna odstupanja, pa se može reći da je u prvom tiražu optička gustina za magenta boja ujednačena.

Tabela 6. Merenja optičke gustine za magentu - tiraž II

\begin{tabular}{|c|c|c|c|c|c|c|c|c|c|c|c|}
\hline \multirow{2}{*}{\multicolumn{2}{|c|}{ Magenta }} & \multicolumn{10}{|c|}{ Tabak } \\
\hline & & 1 & 2 & 3 & 4 & 5 & 6 & 7 & 8 & 9 & 10 \\
\hline \multirow{6}{*}{ 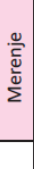 } & 1 & 1,13 & 1,14 & 1,13 & 1,12 & 1,13 & 1,11 & 1,11 & 1,11 & 1,13 & 1,14 \\
\hline & 2 & 1,2 & 1,24 & 1,23 & 1,21 & 1,2 & 1,2 & 1,21 & 1,21 & 1,25 & 1,23 \\
\hline & 3 & 1,14 & 1,18 & 1,16 & 1,16 & 1,12 & 1,16 & 1,17 & 1,15 & 1,19 & 1,19 \\
\hline & 4 & 1,22 & 1,25 & 1,19 & 1,24 & 1,22 & 1,26 & 1,26 & 1,23 & 1,28 & 1,28 \\
\hline & 5 & 1,17 & 1,18 & 1,19 & 1,16 & 1,19 & 1,18 & 1,21 & 1,19 & 1,23 & 1,22 \\
\hline & sr. vred. & 1,172 & 1,198 & 1,18 & 1,178 & 1,172 & 1,182 & 1,192 & 1,178 & 1,216 & 1,212 \\
\hline
\end{tabular}

Kod upoređivanja dobijenih srednjih rezultata koji se nalaze $\mathrm{u}$ tabeli 6 i $\mathrm{u}$ tabeli 7 primećuje se da je $\mathrm{u}$ celokupnim tiražima ujednačena optička gustina magente.
Tabela 7. Merenja optičke gustine za magentu - tiraž III

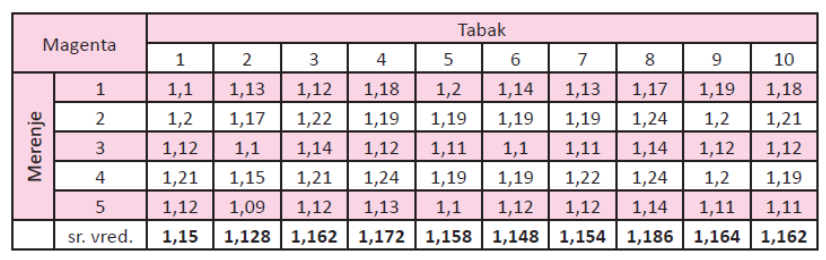

Tabela 8. Merenja optičke gustine za magentu - tiraž IV

\begin{tabular}{|c|c|c|c|c|c|c|c|c|c|c|c|}
\hline \multirow{2}{*}{\multicolumn{2}{|c|}{ Magenta }} & \multicolumn{10}{|c|}{ Tabak } \\
\hline & & 1 & 2 & 3 & 4 & 5 & 6 & 7 & 8 & 9 & 10 \\
\hline \multirow{6}{*}{ 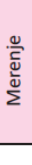 } & 1 & 1,13 & 1,08 & 1,12 & 1,05 & 1,09 & 1,12 & 1,14 & 1,1 & 1,04 & 1,11 \\
\hline & 2 & 1,18 & 1,18 & 1,18 & 1,13 & 1,14 & 1,18 & 1,25 & 1,2 & 1,16 & 1,22 \\
\hline & 3 & 1,1 & 1,12 & 1,11 & 1,09 & 1,14 & 1,1 & 1,17 & 1,11 & 1,08 & 1,14 \\
\hline & 4 & 1,21 & 1,21 & 1,13 & 1,16 & 1,21 & 1,19 & 1,28 & 1,2 & 1,19 & 1,21 \\
\hline & 5 & 1,1 & 1,13 & 1,13 & 1,11 & 1,18 & 1,09 & 1,2 & 1,14 & 1,12 & 1,16 \\
\hline & sr. vred. & 1,144 & 1,144 & 1,134 & 1,108 & 1,152 & 1,136 & 1,208 & 1,15 & 1,118 & 1,168 \\
\hline
\end{tabular}

Kod upoređivanja dobijenih srednjih rezultata koji se nalaze u tabeli 8., takođe postoje zaista minimalna odstupanja, pa se može reći da je kroz celokupan tiraž ujednačen nanos magenta boje.

U tabelama 9-12 predstavljena su merenja optičke gustine za žutu boju.

Tabela 9. Merenja optičke gustine za žutu - tiraž I

\begin{tabular}{|c|c|c|c|c|c|c|c|c|c|c|c|}
\hline \multirow{2}{*}{\multicolumn{2}{|c|}{ Žuta }} & \multicolumn{10}{|c|}{ Tabak } \\
\hline & & 1 & 2 & 3 & 4 & 5 & 6 & 7 & 8 & 9 & 10 \\
\hline \multirow{6}{*}{ 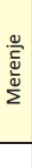 } & 1 & 0,86 & 0,86 & 0,85 & 0,83 & \begin{tabular}{|l|}
0,91 \\
\end{tabular} & 0,87 & 0,85 & 0,89 & 0,91 & 0,91 \\
\hline & 2 & 0,91 & 0,88 & 0,89 & 0,88 & 0,93 & 0,92 & 0,91 & 0,94 & 0,96 & 0,95 \\
\hline & 3 & 0,9 & 0,87 & 0,88 & 0,87 & \begin{tabular}{|l|}
0,91 \\
\end{tabular} & 0,89 & 0,91 & 0,93 & 0,96 & 0,94 \\
\hline & 4 & 0,91 & 0,88 & 0,89 & \begin{tabular}{|l}
0,87 \\
\end{tabular} & \begin{tabular}{|l|}
0,91 \\
\end{tabular} & 0,9 & 0,91 & 0,91 & 0,94 & 0,95 \\
\hline & 5 & 0,86 & 0,83 & 0,86 & \begin{tabular}{|l|}
0,84 \\
\end{tabular} & 0,86 & 0,86 & 0,86 & 0,87 & 0,89 & 0,89 \\
\hline & sr. vred. & 0,888 & 0,864 & 0,874 & 0,858 & 0,904 & 0,888 & 0,888 & 0,908 & 0,932 & 0,928 \\
\hline
\end{tabular}

Kod upoređivanja dobijenih srednjih rezultata koji se nalaze u tabeli 9-12 (tiraži I, II, III i IV) vidi se da je optička gustina žute boje za sve poslove ujednačena.

Tabela 10. Merenja optičke gustine za žutu - tiraž II

\begin{tabular}{|c|c|c|c|c|c|c|c|c|c|c|c|}
\hline \multirow{2}{*}{\multicolumn{2}{|c|}{ Žuta }} & \multicolumn{10}{|c|}{ Tabak } \\
\hline & & 1 & 2 & 3 & 4 & 5 & 6 & 7 & 8 & 9 & 10 \\
\hline \multirow{6}{*}{ 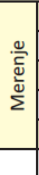 } & 1 & 0,84 & 0,88 & 0,86 & 0,86 & 0,84 & 0,87 & 0,91 & 0,87 & \begin{tabular}{|l|}
0,89 \\
\end{tabular} & 0,89 \\
\hline & 2 & \begin{tabular}{|l|}
0,91 \\
\end{tabular} & 0,96 & 0,94 & 0,93 & 0,9 & 0,93 & 0,91 & 0,93 & \begin{tabular}{|l|}
0,96 \\
\end{tabular} & 0,95 \\
\hline & 3 & 0,9 & 0,91 & 0,91 & 0,9 & 0,87 & 0,91 & 0,91 & \begin{tabular}{|l|}
0,95 \\
\end{tabular} & 0,93 & 0,93 \\
\hline & 4 & 0,93 & 0,96 & 0,94 & 0,94 & 0,91 & 0,93 & 0,93 & 0,91 & 0,96 & 0,96 \\
\hline & 5 & 0,86 & 0,9 & 0,88 & 0,87 & 0,87 & 0,87 & 0,87 & 0,88 & 0,9 & 0,91 \\
\hline & sr. vred. & 0,888 & 0,922 & 0,906 & 0,9 & 0,878 & 0,902 & 0,906 & 0,908 & \begin{tabular}{|l|}
0,928 \\
\end{tabular} & 0,928 \\
\hline
\end{tabular}

Tabela 11. Merenja optičke gustine za žutu - tiraž III

\begin{tabular}{|c|c|c|c|c|c|c|c|c|c|c|c|}
\hline & \multirow{2}{*}{ Žuta } & \multicolumn{10}{|c|}{ Tabak } \\
\hline & & 1 & 2 & 3 & 4 & 5 & 6 & 7 & 8 & 9 & 10 \\
\hline \multirow{6}{*}{ 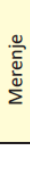 } & 1 & 0,85 & 0,81 & 0,86 & 0,86 & 0,86 & 0,83 & 0,84 & 0,83 & 0,83 & 0,86 \\
\hline & 2 & 0,89 & 0,82 & 0,89 & 0,85 & 0,88 & 0,83 & 0,85 & 0,85 & 0,83 & 0,87 \\
\hline & 3 & 0,88 & 0,81 & 0,88 & 0,85 & 0,85 & 0,83 & \begin{tabular}{|l|}
0,84 \\
\end{tabular} & 0,83 & 0,83 & 0,86 \\
\hline & 4 & 0,94 & 0,86 & 0,93 & 0,94 & 0,93 & 0,9 & 0,91 & 0,92 & 0,89 & 0,91 \\
\hline & 5 & 0,84 & 0,79 & 0,84 & 0,84 & 0,84 & \begin{tabular}{|l|}
0,82 \\
\end{tabular} & 0,8 & 0,81 & 0,79 & 0,8 \\
\hline & sr. vred. & 0,88 & 0,818 & 0,88 & 0,868 & 0,872 & 0,842 & 0,848 & 0,848 & \begin{tabular}{|l|}
0,834 \\
\end{tabular} & 0,86 \\
\hline
\end{tabular}

Tabela 12. Merenja optičke gustine za žutu - tiraž IV

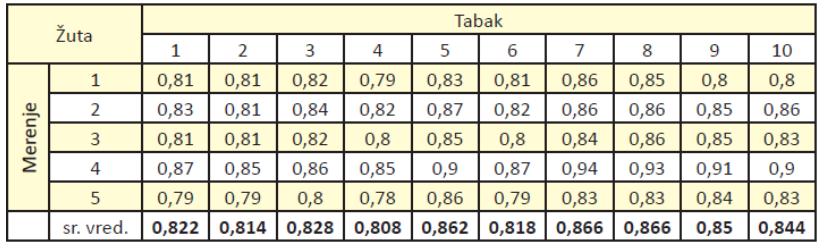

Ujednačene vrednosti optičke gustine za crnu boju se mogu videti u tiražima I i II (tabele 13 i 14), i te vrednosti su za otprilike 0,3 manje od vrednosti optičke gustine za crnu boju kod tiraža III i IV (tabela 15 i 16), pri čemu se 
treba istaći da su i kod tiraža III i IV izmerene ujednačene vrednosti optičke gustine kroz celokupan tiraž.

Tabela 13. Merenja optičke gustine za crnu - tiraž I

\begin{tabular}{|c|c|c|c|c|c|c|c|c|c|c|c|}
\hline \multirow{2}{*}{\multicolumn{2}{|c|}{ Crna }} & \multicolumn{10}{|c|}{ Tabak } \\
\hline & & 1 & 2 & 3 & 4 & 5 & 6 & 7 & 8 & 9 & 10 \\
\hline \multirow{6}{*}{$\Sigma$} & 1 & 1,43 & 1,44 & 1,44 & 1,45 & 1,46 & 1,44 & 1,43 & 1,41 & 1,46 & 1,47 \\
\hline & 2 & 1,56 & 1,53 & 1,5 & 1,5 & 1,58 & 1,57 & 1,53 & 1,51 & 1,53 & 1,55 \\
\hline & 3 & 1,5 & 1,48 & 1,5 & 1,47 & 1,53 & 1,52 & 1,49 & 1,48 & 1,52 & 1,5 \\
\hline & 4 & 1,52 & 1,47 & 1,49 & 1,43 & 1,53 & 1,46 & 1,47 & 1,4 & 1,44 & \begin{tabular}{|l|}
1,47 \\
\end{tabular} \\
\hline & 5 & 1,47 & 1,44 & 1,49 & 1,45 & 1,52 & 1,49 & 1,46 & 1,46 & 1,51 & 1,48 \\
\hline & sr. vred & 1,496 & 1,472 & 1,484 & 1,46 & 1,524 & 1,496 & 1,476 & 1,452 & 1,492 & $\mid 1,494$ \\
\hline
\end{tabular}

Tabela 14. Merenja optičke gustine za crnu - tiraž II

\begin{tabular}{|c|c|c|c|c|c|c|c|c|c|c|c|}
\hline \multirow{2}{*}{\multicolumn{2}{|c|}{ Crna }} & \multicolumn{10}{|c|}{ Tabak } \\
\hline & & 1 & 2 & 3 & 4 & 5 & 6 & 7 & 8 & 9 & 10 \\
\hline \multirow{6}{*}{$\Sigma$} & 1 & 1,49 & 1,45 & 1,42 & 1,43 & 1,39 & 1,41 & 1,39 & 1,39 & 1,44 & 1,42 \\
\hline & 2 & 1,56 & 1,51 & 1,47 & 1,48 & 1,46 & 1,47 & 1,46 & 1,48 & 1,52 & 1,53 \\
\hline & 3 & 1,49 & 1,46 & 1,41 & 1,45 & 1,39 & 1,44 & 1,41 & 1,43 & \begin{tabular}{|l|l}
1,46 \\
\end{tabular} & 1,42 \\
\hline & 4 & 1,45 & 1,46 & 1,44 & 1,45 & 1,39 & 1,43 & 1,45 & 1,46 & 1,5 & 1,49 \\
\hline & 5 & 1,44 & 1,4 & 1,39 & 1,4 & 1,34 & 1,36 & 1,37 & 1,41 & 1,44 & 1,39 \\
\hline & sr. vred. & 1,486 & 1,456 & 1,426 & 1,442 & 1,394 & 1,422 & 1,416 & 1,434 & 1,472 & 1,45 \\
\hline
\end{tabular}

Tabela 15. Merenja optičke gustine za crnu - tiraž III

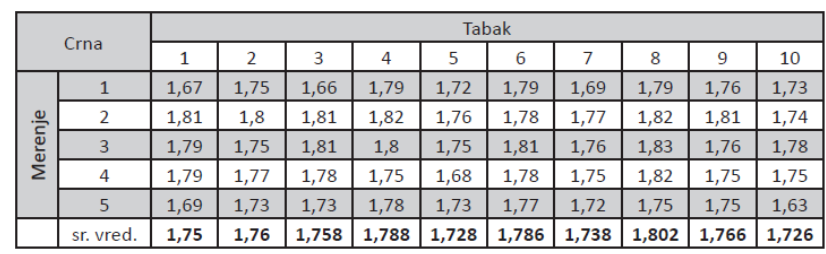

Tabela 16. Merenja optičke gustine za crnu - tiraž IV

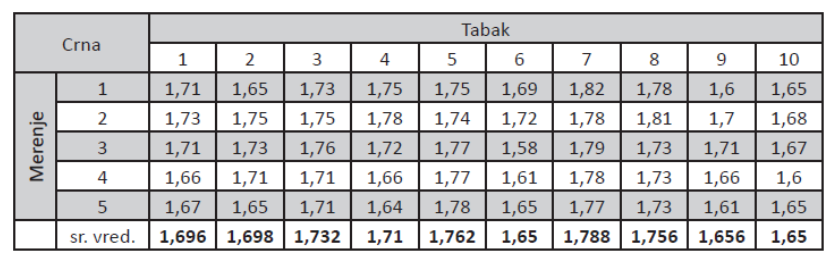

Merenja optičke gustine za Pantone boje P186 C su predstavljena u tabelama 17-20.

Tabela 17. Merenja optičke gustine za P186 C - tiraž I

\begin{tabular}{|c|c|c|c|c|c|c|c|c|c|c|c|}
\hline \multicolumn{2}{|c|}{$\mathrm{P} 186 \mathrm{C}$} & \multicolumn{10}{|c|}{ Tabak } \\
\cline { 2 - 13 } & 1 & 2 & 3 & 4 & 5 & 6 & 7 & 8 & 9 & 10 \\
\hline \multirow{4}{*}{} & 1 & 1,63 & 1,57 & 1,59 & 1,62 & 1,61 & 1,64 & 1,59 & 1,59 & 1,59 & 1,62 \\
\cline { 2 - 12 } & 2 & 1,57 & 1,54 & 1,55 & 1,48 & 1,57 & 1,59 & 1,6 & 1,6 & 1,61 & 1,62 \\
\cline { 2 - 11 } & 3 & 1,63 & 1,61 & 1,61 & 1,58 & 1,63 & 1,63 & 1,61 & 1,63 & 1,63 & 1,63 \\
\cline { 2 - 11 }$\Sigma$ & 4 & 1,66 & 1,63 & 1,66 & 1,65 & 1,66 & 1,64 & 1,65 & 1,66 & 1,69 & 1,68 \\
\cline { 2 - 11 } & 5 & 1,58 & 1,59 & 1,62 & 1,58 & 1,61 & 1,61 & 1,59 & 1,61 & 1,6 & 1,62 \\
\hline & sr. vred. & 1,614 & 1,588 & 1,606 & 1,582 & 1,616 & 1,622 & 1,608 & 1,618 & 1,624 & 1,634 \\
\hline
\end{tabular}

Tabela 18. Merenja optičke gustine za P186 C - tiraž II

\begin{tabular}{|c|c|c|c|c|c|c|c|c|c|c|c|}
\hline \multirow{2}{*}{\multicolumn{2}{|c|}{ P186 C }} & \multicolumn{10}{|c|}{ Tabak } \\
\hline & & 1 & 2 & 3 & 4 & 5 & 6 & 7 & 8 & 9 & 10 \\
\hline \multirow{6}{*}{  } & 1 & 1,61 & 1,56 & 1,61 & 1,52 & 1,54 & 1,61 & 1,56 & 1,55 & 1,57 & 1,6 \\
\hline & 2 & 1,56 & 1,6 & 1,53 & 1,56 & 1,52 & 1,55 & 1,58 & 1,53 & 1,55 & 1,57 \\
\hline & 3 & 1,63 & 1,64 & 1,56 & 1,63 & 1,58 & 1,6 & 1,62 & 1,58 & 1,61 & 1,6 \\
\hline & 4 & 1,63 & 1,68 & 1,64 & 1,65 & 1,63 & 1,59 & 1,65 & 1,62 & 1,65 & 1,63 \\
\hline & 5 & 1,61 & 1,62 & 1,57 & 1,59 & 1,55 & 1,57 & 1,59 & 1,55 & 1,59 & 1,56 \\
\hline & sr. vred. & 1,608 & 1,62 & 1,582 & 1,59 & 1,564 & 1,584 & 1,6 & 1,566 & 1,594 & 1,592 \\
\hline
\end{tabular}

Tabela 19. Merenja optičke gustine za P186 C - tiraž III

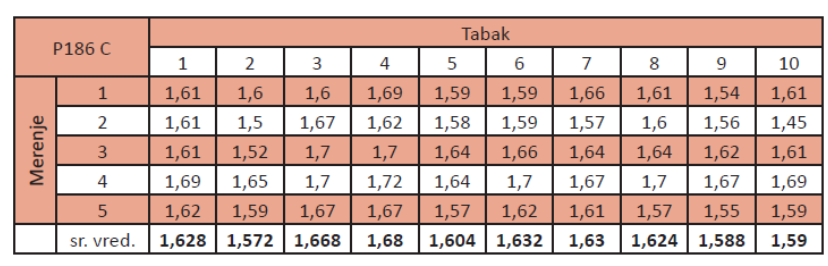

Tabela 20. Merenja optičke gustine za P186 C - tiraž IV

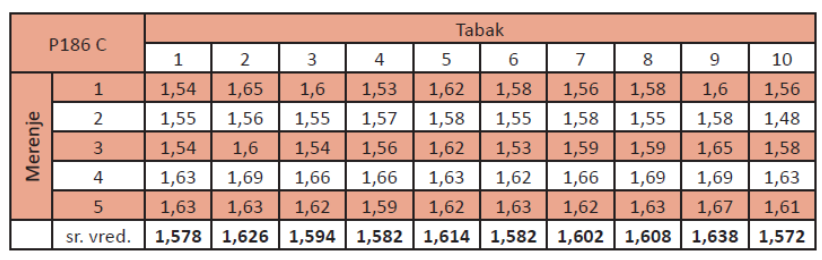

\subsection{Merenje sivog balansa}

Kod merenja sivog balansa (polja za sivi balans od 50\%), uređaj se kalibriše na papiru, pri čemu su na svakom tabaku vršena četiri merenja od kojih je dobijena srednja vrednost za upoređivanje. Dobijeni rezultati su predstavljeni u tabelama 21-24.

Tabela 21. Merenje sivog balansa - tiraž I

\begin{tabular}{|c|c|c|c|}
\hline Tabak & $\mathrm{C}(36)$ & $\mathrm{M}(28)$ & $\mathrm{Y}(25)$ \\
\hline 1 & 0,225 & 0,283 & 0,310 \\
\hline 2 & 0,213 & 0,265 & 0,298 \\
\hline 3 & 0,220 & 0,268 & 0,303 \\
\hline 4 & 0,213 & 0,258 & 0,288 \\
\hline 5 & 0,243 & 0,298 & 0,328 \\
\hline 6 & 0,243 & 0,288 & 0,320 \\
\hline 7 & 0,215 & 0,280 & 0,310 \\
\hline 8 & 0,225 & 0,288 & 0,318 \\
\hline 9 & 0,238 & 0,300 & 0,328 \\
\hline 10 & 0,238 & 0,293 & 0,323 \\
\hline sr. vred. & $\mathbf{0 , 2 2 7}$ & $\mathbf{0 , 2 8 2}$ & $\mathbf{0 , 3 1 2}$ \\
\hline
\end{tabular}

Iz tabele 21. vidi se da je u tiražu I dominantna žuta boja, posle nje magenta i na kraju cijan, što je zabeleženo i prilikom merenja sivog balansa za tabake odštampane u tiražu II.

Tabela 22. Merenje sivog balansa - tiraž II

\begin{tabular}{|c|c|c|c|}
\hline Tabak & $\mathrm{C}(36)$ & $\mathrm{M}(28)$ & $\mathrm{Y}(25)$ \\
\hline 1 & 0,248 & 0,293 & 0,318 \\
\hline 2 & 0,268 & 0,320 & 0,348 \\
\hline 3 & 0,258 & 0,293 & 0,320 \\
\hline 4 & 0,245 & 0,293 & 0,320 \\
\hline 5 & 0,250 & 0,288 & 0,315 \\
\hline 6 & 0,253 & 0,293 & 0,325 \\
\hline 7 & 0,238 & 0,280 & 0,318 \\
\hline 8 & 0,240 & 0,275 & 0,315 \\
\hline 9 & 0,245 & 0,290 & 0,330 \\
\hline 10 & 0,243 & 0,285 & 0,330 \\
\hline Sr. Vre. & $\mathbf{0 , 2 4 9}$ & $\mathbf{0 , 2 9 1}$ & $\mathbf{0 , 3 2 4}$ \\
\hline
\end{tabular}

Tabela 23. Merenje sivog balansa - tiraž III

\begin{tabular}{|c|c|c|c|}
\hline Tabak & $\mathrm{C}(36)$ & $\mathrm{M}(28)$ & $\mathrm{Y}(25)$ \\
\hline 1 & 0,248 & 0,288 & 0,345 \\
\hline 2 & 0,238 & 0,285 & 0,328 \\
\hline 3 & 0,250 & 0,295 & 0,345 \\
\hline 4 & 0,230 & 0,290 & 0,343 \\
\hline 5 & 0,243 & 0,290 & 0,343 \\
\hline 6 & 0,238 & 0,288 & 0,338 \\
\hline 7 & 0,218 & 0,268 & 0,318 \\
\hline 8 & 0,245 & 0,295 & 0,333 \\
\hline 9 & 0,250 & 0,293 & 0,340 \\
\hline 10 & 0,245 & 0,293 & 0,343 \\
\hline sr. vred. & $\mathbf{0 , 2 4 0}$ & $\mathbf{0 , 2 8 8}$ & $\mathbf{0 , 3 3 7}$ \\
\hline
\end{tabular}

Za sve tiraže može se uočiti ujednačenost optičke gustine. 
Slični rezultati su dobijeni i za tiraže III i IV, tj i ovde su najveće vrednosti za žutu boju, pa posle magenta i na kraju cijan boju.

Tabela 24. Merenje sivog balansa - tiraž IV

\begin{tabular}{|c|c|c|c|}
\hline Tabak & $\mathrm{C}(36)$ & $\mathrm{M}(28)$ & $\mathrm{Y}(25)$ \\
\hline 1 & 0,213 & 0,263 & 0,313 \\
\hline 2 & 0,240 & 0,290 & 0,340 \\
\hline 3 & 0,223 & 0,275 & 0,318 \\
\hline 4 & 0,240 & 0,280 & 0,330 \\
\hline 5 & 0,208 & 0,260 & 0,313 \\
\hline 6 & 0,243 & 0,293 & 0,350 \\
\hline 7 & 0,238 & 0,283 & 0,340 \\
\hline 8 & 0,223 & 0,265 & 0,325 \\
\hline 9 & 0,238 & 0,280 & 0,338 \\
\hline 10 & 0,253 & 0,295 & 0,343 \\
\hline Sr. Vre. & $\mathbf{0 , 2 3 2}$ & $\mathbf{0 , 2 7 8}$ & $\mathbf{0 , 3 3 1}$ \\
\hline
\end{tabular}

\section{ZAKLJUČAK}

Prilikom merenja optičke gustine, srednja vrednost za cijan se između tiraža kretala od 0,66 do 0,83 . Kod tiraža I i II je to bilo prilično ujednačeno, dok su kod tiraža III i IV zabeležene male varijacije, ali ta odstupanja nisu velika. Vrednosti optičke gustine za magenta boju se kreću od 1,11 do 1,32.

Postoje male razlika u tiražima i između tiraža, ali odstupanja nisu velika. Srednja vrednost optičke gustine za žutu boju se kreće od 0,81 do 0,93 i kod nje je nanos u okviru tiraža prilično ujednačen.

Kod srednje vrednosti optičke gustine za crnu boju beleže se najveća odstupanja. Optička gustina se kreće od 1,39 do 1,79. Kod tiraža I i II vrednost je bila prilično ujednačena i kretala se između 1,4-1,5, ali kod tiraža III i IV je nanos crne pojačan za oko 0,3 . Ujednačen nanos je izmeren i za Pantone boju P186 C i kreće se oko 1,6.
Zbog specifičnosti posla, na tabaku dominiraju žutonarandžasti tonovi, dok plave ima jako malo. Zbog toga, a i zbog referentnog uzorka, magenta i žuta boja su jače štampane u odnosu na cijan, što za rezultat daje sivi banas koji je pomeren prema toplijim bojama.

Možemo se reći da je kontrola kvaliteta otisaka prilikom štampe veoma bitna stvar, jer se sa njom prate, podešavaju i održavaju zadate vrednosti. Uvek će biti malih varijacija štampe između tiraža, ali se sa konstantnim praćenjem $i$ merenjem te varijacije mogu svesti na minimum i može se dobiti postojanost i ponovljivost kvaliteta otisaka.

Nakon izvršene kontrole kvaliteta ofset štampe u štampariji Balaton, može se reći da su dobijeni dobri rezultati i da se može reći da su u pitanju kvalitetno odrađeni poslovi.

\section{LITERATURA}

[1] Novaković, D. (2008) Uvod u grafičke tehnologije, Fakultet Tehničkih Nauka, Novi Sad

[2] Novaković, D. (2013) Grafički procesi, skripta, Fakultet Tehničkih Nauka, Novi Sad

[3] Novaković D., Pavlović Ž., Karlović I., Pešterac Č. (2009) Reprodukciona tehnika, priručnik za vezbe, Fakultet Tehničkih Nauka, Novi Sad

\section{Podaci za kontakt:}

MSc Boris Hudak, kadet10@gmail.com Dr Nemanja Kašiković, knemanja@uns.ac.rs Dr Rastko Milošević, rastko.m@uns.ac.rs 